\title{
Right paratracheal mass on chest X-ray: an important part of the checklist before cardiac catheterisation
}

\author{
Neeraj Ganju, Arvind Kandoria, Kunal Mahajan, Rajesh Sharma
}

Department of Cardiology, Indira Gandhi Medical College, Shimla, Himachal Pradesh, India

\section{Correspondence to} Dr Kunal Mahajan, kunalmahajan442@gmail.com

Accepted 22 January 2016

\section{DESCRIPTION}

Infrahepatic inferior vena cava (IVC) interruption with azygos continuation is a rare congenital anomaly with a prevalence of $0.6-2.0 \%$ in patients with congenital heart disease. ${ }^{1}$ Many of these patients are expected to undergo cardiac catheterisation through the femoral vein. For this, the catheter must pass up the IVC to the azygos vein and then down into the superior vena cava (SVC), making the procedure technically more difficult. A 19-year-old male patient with patent ductus arteriosus with severe pulmonary arterial hypertension was subjected to cardiac catheterisation to test the reactivity of the pulmonary vascular bed. Chest $\mathrm{X}$-ray revealed a smooth mass at the right tracheobronchial angle (figure 1). During right heart

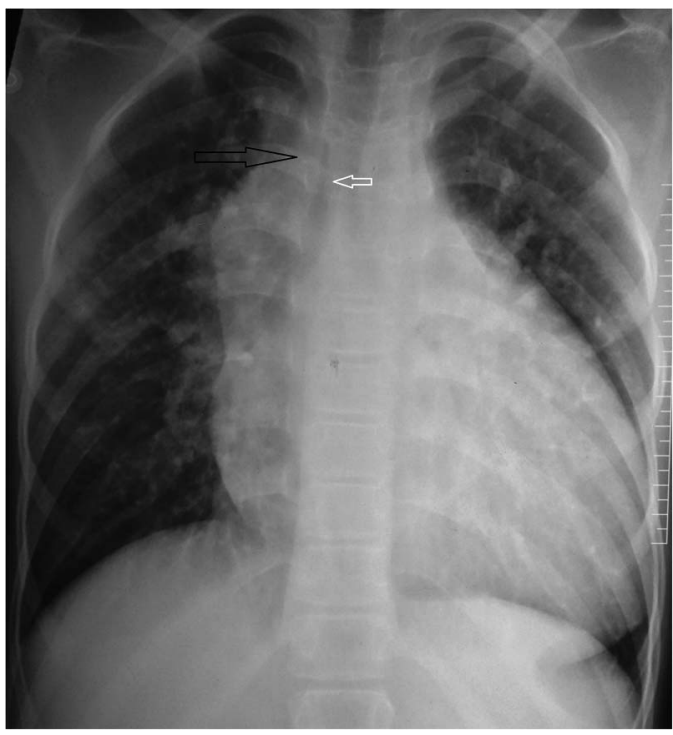

Figure 1 Chest X-ray, posteroanterior view, showing a paratracheal smooth mass (black arrow) to the right of right tracheobronchial angle (white arrow).

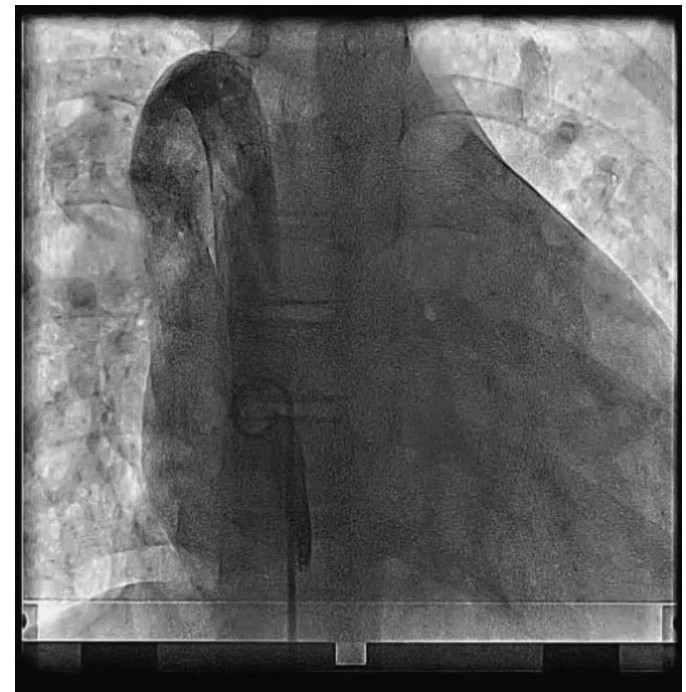

Video 1 Venogram performed through a pigtail catheter placed in the dilated azygos vein. Note the azygos vein draining into the superior vena cava and then into the right atrium.
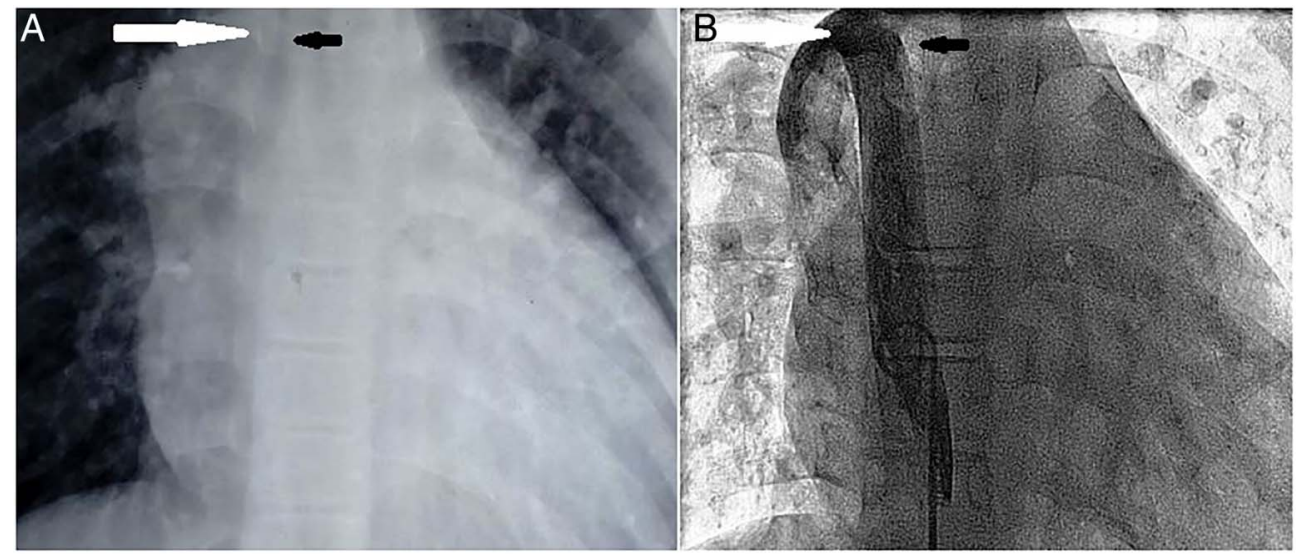

Figure 2 Comparison of the chest X-ray film and the fluoroscopic image. (A) Chest X-ray, posteroanterior view, showing a smooth mass (white arrow) to the right of right tracheobronchial angle (black arrow). (B) Fluoroscopic image of venogram taken through a pigtail catheter placed in the dilated azygos vein. White arrow represents the dilated azygos vein entering the superior vena cava, corresponding to the smooth mass on chest X-ray while the black arrow corresponds to the right tracheobronchial angle. 


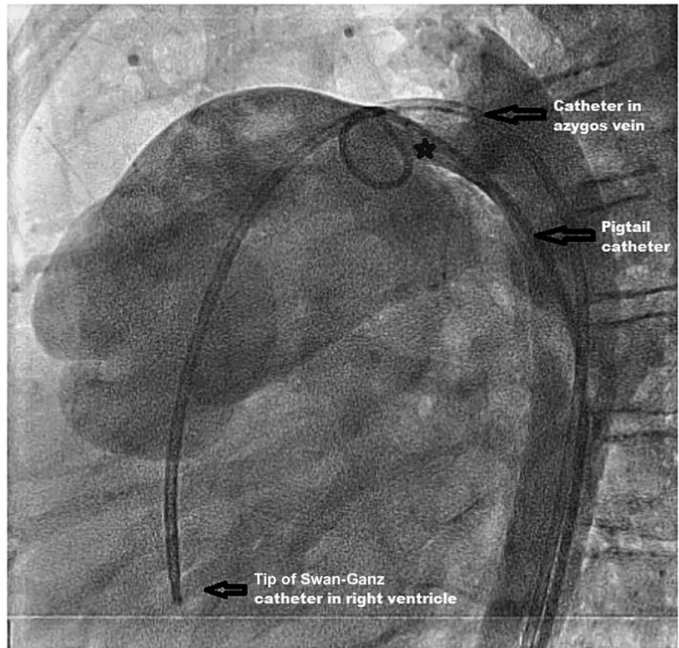

Figure 3 Lateral view showing a pigtail catheter advanced into the pulmonary artery from the aorta via a large patent ductus arteriosus (star mark). Also note the Swan-Ganz catheter that has a course from the right femoral vein to the dilated azygos vein, to the superior vena cava, to the right atrium and finally to the right ventricle (only the catheter course is seen, venogram not available).

catheterisation, there was difficulty in negotiating the wire from the IVC to the right atrium. On manipulation, the wire took a course from the IVC to the SVC to the right atrium. Venogram

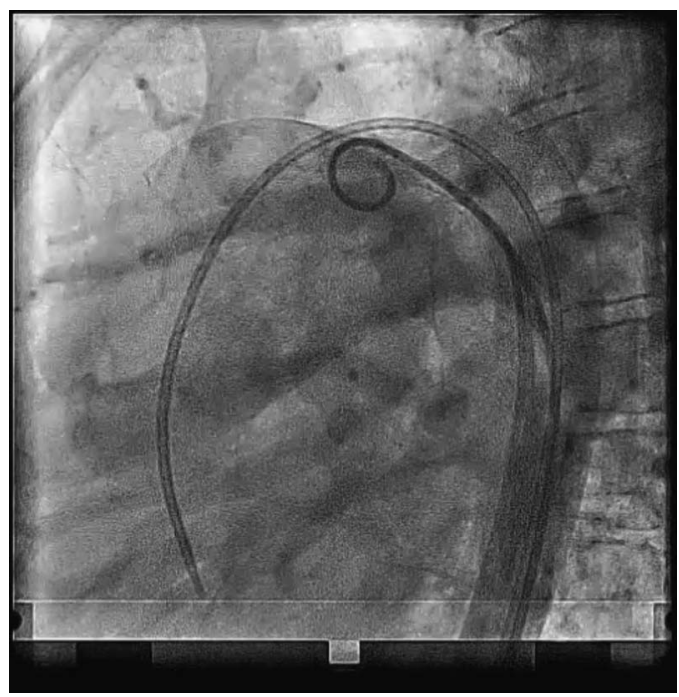

Video 2 Lateral view showing a large patent ductus arteriosus. Also, the catheter course of the Swan-Ganz catheter shown from azygos vein up to the right ventricle. was carried out, which showed a dilated azygos vein draining into the SVC (figure 2B, video 1). Catheter manipulation from the right ventricle into the pulmonary artery could not be performed because of this anomalous course. Finally, the catheter was advanced through the aorta into the pulmonary artery via the large-sized ductus (figure 3, video 2). This case thus highlights the significance of a dilated azygos vein on the precatheterisation chest X-ray. Differential diagnosis includes tumour, adenopathy or dilated vessel (right aortic arch, dilated aberrant right subclavian artery and azygos dilation, which may be idiopathic or secondary to SVC obstruction, congestive heart failure and aortoazygos fistula). ${ }^{2} 3$

\section{Learning points}

- Interrupted inferior vena cava (IVC) with azygos continuation is seen in $0.6-2 \%$ of patients with congenital heart disorders.

- Presence of a smooth right paratracheal mass at the right tracheobronchial angle on chest X-ray should raise the possibility of interrupted IVC with azygos continuation.

- Differential diagnosis includes tumours, lymphadenopathy and azygos venous dilation because of other causes such as aortoazygos fistula, congestive heart failure, SVC obstruction and idiopathic.

- This case reinforces the knowledge of anatomy on a posteroanterior/anteroposterior chest X-ray and highlights an important reminder for the cardiologist before diagnostic and therapeutic cardiac catheterisation.

Competing interests None declared.

Patient consent Obtained.

Provenance and peer review Not commissioned; externally peer reviewed.

\section{REFERENCES}

1 Timmers GJ, Falke TH, Rauwerda JA, et al. Deep vein thrombosis as a presenting symptom of congenital interruption of the inferior vena cava. Int J Clin Pract 1999:53:75-6.

2 Dudiak CM, Olson MC, Posniak HV. CT evaluation of congenital and acquired abnormalities of the azygos system. Radiographics 1991;11:233-46.

3 Kim CY, Mirza RA, Bryant JA, et al. Central veins of the chest: evaluation with time-resolved MR angiography. Radiology 2008;247:558-66.

Copyright 2016 BMJ Publishing Group. All rights reserved. For permission to reuse any of this content visit

http://group.bmj.com/group/rights-licensing/permissions.

BMJ Case Report Fellows may re-use this article for personal use and teaching without any further permission.

Become a Fellow of BMJ Case Reports today and you can:

- Submit as many cases as you like

- Enjoy fast sympathetic peer review and rapid publication of accepted articles

- Access all the published articles

- Re-use any of the published material for personal use and teaching without further permission

For information on Institutional Fellowships contact consortiasales@bmjgroup.com

Visit casereports.bmj.com for more articles like this and to become a Fellow 